\title{
EL CONTROL DE CONSTITUCIONALIDAD DE LAS LEYES EN ESPAÑA
}

\author{
Francisco Carruitero Lecca*
}

\begin{abstract}
Resumen
El control de constitucionalidad de las leyes es un mecanismo que constituye elemento medular en el forjamiento del Estado Constitucional de Derecho, toda vez que hace posible en la práctica el principio de la supremacía constitucional.

En ese sentido, el modelo español es uno de los mejores logrados, sobretodo gracias a la presencia del Tribunal Constitucional que a través de su jurisprudencia ha establecido una línea indiscutible de un sistema que privilegia ante todo las normas constitucionales. Por ello, en el presente trabajo desarrollaremos el sistema de control de constitucionalidad de las leyes en España: desde los órganos que lo ejercen hasta los mecanismos que lo hacen posible.

Palabras clave: Control constitucional - incosntitucionalidad - Tribunal Constitucional.
\end{abstract}

\begin{abstract}
The control of the constitutionality of the laws is a mechanism that constitutes a medullar element in the creation of a Constitutional State of the Rights, it actually makes possible the practice of the constitutional supremacy.

In order to that, the model applied in Spain is one the best obtained, specially thanks to the presence of the Constitutional Court that through its jurisprudente established an unquestionable line that privileges the constitutional norms. For this reason, in the present article we develop the control system of constitutionality of the laws in Spain: from the organs that manage it to the mechanisms that make it possible.
\end{abstract}

Key words: Constitutional control - unconstitutional - Constitutional Court.

\section{Sumario}

1. Antecedentes del control de constitucionalidad de las leyes en España. 2. El modelo de control constitucional español. 3. El rol del Tribunal Constitucional. 4. El recurso de inconstitucionalidad. 5. La cuestión de inconstitucionalidad. 6. La cuestión interna de inconstitucionalidad. 7. Conclusiones.

* Doctor en Derecho y Magíster en Sociología. Profesor de la Pontificia Universidad Católica del Perú. 


\section{ANTECEDENTES DEL CONTROL DE CONSTITUTICIONALIDAD DE LAS LEYES EN ESPAÑA}

La evolución del poder en Europa, d urante todo el siglo XIX, se dio de tal forma que fue el Parlamento, totalmente soberano, el órgano con la última palabra en los asuntos legislativos, tanto en su aspecto formal como material. De esta manera, no estaba sometido a los límites de una Constitución, atendiendo a que esta no era una norma suprema, y a la vez, era inaceptable que los tribunales controlaran la ley.

En efecto, los primeros antecedentes del control de la constitucionalidad se encuentran en los Estados Federales de Austria y Alemania de finales del siglo XIX. Ello, por cuanto en un Estado Federal coexistían el legislador federal y los legisladores estatales, produciéndose conflictos entre las leyes dada por ambos grupos: muchas veces una ley dada por un legislador federal colisionaba contra una dada por el legislador estatal. Así, para garantizar la unidad normativa se establecieron medidas como que el Derecho Federal prevalecía sobre el estatal, lo que dio lugar a muchas críticas doctrinales sobre todo en Alemania, pidiendo que los tribunales, como verdaderos intérpretes, controlen las leyes de la federación, situación que se hizo realidad después de la Primera Guerra Mundial.

Es con Hans Kelsen ${ }^{1}$, que surge en Austria la justicia constitucional y el primer Tribunal Constitucional. Se intenta aquí defender la necesidad de control de las leyes partiendo de su propia concepción del derecho y de una pirámide normativa. Planteó que cualquier norma de rango inferior a la Constitución que vaya en contra de esta es inconstitucional, y así debe ser efectivamente declarada para poder surtir todos los efectos que correspondan. Esta tarea no es asignada a todos los jueces del Estado, es un tribunal especial, el Tribunal Constitucional, el encargado de aplicar la Constitución frente a las leyes, teniendo la facultad de derogarlas.

Sin embargo, en España durante todo el siglo XIX no existió ninguna fórmula de control de constitucionalidad de leyes; es recién en la Segunda República, con la Constitución Republicana de 1931, que se crea un Tribunal de Garantías Constitucionales. Este órgano tuvo caracteres muy politizados, por lo que al momento de la ejecución de sus sentencias, los efectos que deberían haberse sucedido se pasaban por alto, siendo que en la práctica sus sentencias no se acataban².

Asimismo, las profundas contradicciones de la sociedad española de los años veinte y treinta desembocaron en la Guerra Civil, luego de la cual se instauró 
la dictadura del General Francisco Franco, quien derogó la Constitución Republicana de 1931, dando lugar a las Leyes Fundamentales del Reino (que tuvieron vigencia hasta la aprobación de la Constitución Democrática de 1978), que no incluyeron un organismo de control de la constitucionalidad de las leyes, lo que era de esperarse debido a la ausencia de una Constitución en sentido estricto. Así, era un Tribunal Supremo el encargado de ejercer todo tipo de control legal.

En consecuencia, es con la restauración de la democracia en España, reflejada en el sistema constitucional de la Carta de 1978, que en este Estado va empezar a tener institucionalidad un efectivo control de las leyes a la luz de su correspondencia con la Constitución.

\section{EL MODELO DE CONTROL CONSTITUCIONAL ESPAÑOL}

Es bien sabido que el sistema europeo de control de constitucionalidad de las leyes se basa en concentrar ese poder en un solo organismo. No obstante, en el caso de España existe una jurisdicción constitucional atribuida al Tribunal Constitucional y también a los tribunales ordinarios. Las atribuciones dadas difieren en cuanto a sus alcances y efectos, pero en ambos casos, implican una observación de una norma de rango inferior a la Constitución.

En lo que corresponde a los jueces ordinarios, estos poseen la capacidad de determinar la compatibilidad de la norma o acto inferior con respecto a la norma superior, esto es denominado derecho de comprobación de constitucionalidad (Prüfungsrecht) ${ }^{3}$.

El Tribunal Constitucional, por su lado, posee la competencia para declarar la nulidad de una norma que no haya superado la comprobación de constitucionalidad. (Verwerfungkompetenz). Es de observarse que es éste el único órgano que puede ostentar la competencia de rechazo sobre las normas con rango de ley.

En el caso de que un tribunal ordinario se encuentre con una norma con rango legal, sólo tendrá disponible el derecho de comprobación, debiendo acudir al Tribunal Constitucional mediante la cuestión de inconstitucionalidad para que este se pronuncie, pues es el único órgano que posee la competencia de rechazo normativo. En el supuesto de que se trate de una norma infralegal, cualquier tribunal ordinario tendrá atribuidas ambas capacidades, pudiendo ejercer su competencia de rechazo normativo, inaplicándolos o declarándolos nulos, según sea el procedimiento. 
Bajo estas consideraciones podemos afirmar que España posee un sistema de control constitucional que puede ser denominado concentrado, pero con atribuciones de observancia obligatoria otorgadas, a manera de control difuso impropio, a los jueces ordinarios. Existe una cierta competencia compartida del Tribunal Constitucional con otros órganos del Estado. Es tal la importancia de esta última característica, que cuando un juez observa una norma, el proceso sobre el que recae la norma mencionada se suspende hasta que el Tribunal Constitucional haya emitido la resolución en la que determina la constitucionalidad o inconstitucionalidad de la ley.

\section{EL ROL DEL TRIBUNAL CONSTITUCIONAL}

La Constitución de España establece en su Título IX que el Tribunal Constitucional es uno de los órganos constitucionales, al que concretamente se confía la defensa de la Carta Fundamental en la dimensión jurídica y por métodos y formas jurisdiccionales. Así, con la aprobación de Su Majestad el Rey, desde el día 12 de julio de 1980, el Tribunal Constitucional viene ejerciendo las competencias que le imponen la Constitución y su Ley Orgánica ${ }^{4}$.

Las normas constitucionales sobre el Tribunal han sido desarrolladas con mayor detalle en la Ley Orgánica de la materia $\mathrm{N}^{0} 2 / 1979$, del 3 de octubre. En este cuerpo normativo, de acuerdo con la propia Constitución (Artículo $165^{\circ}$ ), se regula el funcionamiento del Tribunal, así como el estatuto de sus miembros, el procedimiento a seguir ante él y las condiciones para el ejercicio de las acciones. Asimismo, en atención de la potestad reglamentaria reconocida por su propia Ley Orgánica (Artículo $\left.2^{\circ} .2\right)^{5}$, el Tribunal dictó, con fecha 5 de julio de 1990, el actual Reglamento de Organización y Personal, que regula su actividad.

Un aspecto a resaltar es que en España se ha institucionalizado que el Tribunal Constitucional es el intérprete supremo de la Constitución (Artículo $1^{\circ} .1$ Ley Orgánica), además de ser un órgano constitucional e independiente de cualquier otro, no formando parte del Poder Judicial y sometido únicamente a la Constitución y a su propia Ley Orgánica.

Efectivamente, la Constitución y su Ley Orgánica recogen otros dispositivos sobre las sentencias del Tribunal Constitucional que guardan coherencia la calidad de máximo intérprete de la Constitución del Tribunal Constitucional. Así, se establece que las sentencias recaídas en procesos de inconstitucionalidad "tienen plenos efectos frente a todos" (Artículo 
$164^{\circ} .1$ Constitución) y "vincularán a todos los poderes públicos" (Artículo $38^{\circ} .1$ Ley Orgánica). Ello, como resulta lógico, implica el otorgamiento de especiales efectos a las resoluciones del Tribunal, los que suponen que su doctrina ha de informar la actividad de todos los poderes públicos.

De igual manera, es importante mencionar que las decisiones del Tribunal Constitucional no pueden ser recurridas en al ámbito interno y tienen calidad de cosa juzgada. En consecuencia, un asunto resuelto por el Tribunal, no puede volver a plantearse ante él. Sin embargo, sí se permite que problemas similares sí puedan reproducirse ante el Tribunal Constitucional, siempre que permitan actualizar su doctrina y adecuar la interpretación constitucional a la realidad histórica.

El Tribunal Constitucional está integrado por doce miembros ${ }^{6}$ nombrados por el Rey. Dicha conformación es la siguiente: cuatro a propuesta del Congreso de los Diputados (por mayoría de tres quintos de sus miembros), cuatro a propuesta del Senado (con idéntica mayoría), dos a propuesta del Gobierno y dos a propuesta del Consejo General del Poder Judicial (Artículo $159^{\circ} .1$ Constitución).

Así también, los Magistrados del Tribunal Constitucional son elegidos por mandato constitucional entre juristas de reconocida competencia, siendo independientes e inamovibles. La duración del cargo es de nueve años sin posibilidad de reelección inmediata, sin que la Ley haya previsto límite de edad para su desempeño. Finalmente, es pertinente señalar que con el fin de asegurar la continuidad en las actuaciones del Tribunal, éste se renueva por terceras partes cada tres años (Artículo $159^{\circ} .3$ Constitución).

Ahora bien, respecto de las competencias del Tribunal, estas se han establecido en el artículo $161^{\circ}$ de la Constitución y en el artículo $2^{\circ} .1$ de su Ley Orgánica, dentro de las que se encuentran las siguientes:

\subsection{Control de constitucionalidad de normas con rango de ley}

Se hace a través del recurso de inconstitucionalidad y de la cuestión de inconstitucionalidad, y corresponden a las normas del Estado y de las Comunidades Autónomas. El primero es un recurso directo y abstracto, promovido por el Presidente del Gobierno, el Defensor del Pueblo, cincuenta Diputados o Senadores y los Gobiernos y Parlamentos autonómicos. El segundo es un recurso concreto. 


\subsection{Conflictos constitucionales}

Pueden ser entre el Estado y una o más Comunidades Autónomas o de dos o más Comunidades Autónomas entre sí; o entre órganos constitucionales del Estado. Los conflictos entre órganos constitucionales pueden enfrentar al Gobierno de la Nación, al Congreso de los Diputados, al Senado y al Consejo General del Poder Judicial entre sí, y tienen por finalidad la determinación de sus respectivas atribuciones competenciales.

\subsection{Conflicto en defensa de la autonomía local}

Es promovido por municipios y provincias contra normas con rango de ley, estatales o autonómicas, que contravengan la autonomía local constitucionalmente garantizada.

\subsection{Control previo de constitucionalidad de Tratados Internacional es}

Este control se da a requerimiento del Gobierno, del Congreso o del Senado. Es un procedimiento para evitar la integración en el Derecho español de normas internacionales contrarias a la Constitución. Un ejemplo de este control fue el que se desarrolló con ocasión de que España sólo podía integrar el Tratado de Maastricht si previamente se reformaba el artículo $13^{\circ} .2$ de la Constitución, lo que efectivamente se hizo en agosto de 1992, siendo que el caso concluyó con la Declaración $N^{0} 1 / 2004$, donde se estableció que no hacía falta modificar la Constitución para incorporar la Constitución Europea ${ }^{7}$.

\subsection{Recurso de amparo}

Puede ser interpuesto por cualquier persona, nacional o extranjera, física o jurídica, para proteger los derechos reconocidos en los artículos $14^{\circ}$ al $30^{\circ}$ de la Constitución.

Para efectos de este trabajo, estudiaremos la primera de las competencias del Tribunal Constitucional, que es precisamente la que le otorga la atribución de ser el supremo garantista de la supremacía de la Constitución sobre otras normas de rango inferior o de las leyes para hablar de inconstitucionalidad en sentido estricto. Esta primera competencia le permite al Tribunal conocer, como instancia única, los recursos de inconstitucionalidad y las cuestiones de inconstitucionalidad. 


\section{EL RECURSO DE INCONSTITUCIONALIDAD}

El recurso de inconstitucionalidad, establecido en el artículo $161^{\circ} .1$ de la Constitución, se configura como el primer instrumento procesal para controlar la constitucionalidad de las normas con fuerza de ley. Se caracteriza por tratarse de una acción jurisdiccional nacida precisamente con el fin de controlar la adecuación a la Constitución de las normas con fuerza de ley; se trata de una impugnación directa de la norma.

En cuanto a la legitimación, pueden interponer el recurso de inconstitucional, según el artículo $162^{\circ} .1$ de la Constitución española, el Presidente del Gobierno, el Defensor del Pueblo, cincuenta Diputados, cincuenta Senadores, los órganos colegiados ejecutivos de las Comunidades Autónomas y las Asambleas de las Comunidades Autónomas. Entonces, la legitimación para recurrir directamente normas con fuerza de ley se encuentra restringida, situación que guarda coherencia con la realidad de la mayoría de los países que tiene un control concentrado de constitucionalidad de las leyes, de manera que sólo determinados órganos o instancias políticas pueden impugnar este tipo de normas; se excluye, así, que cualquier persona, distinta de las facultadas, pueda recurrir a este recurso. ${ }^{8}$

En relación con lo anterior se puede decir que la restricción de la legitimación en este extremo, radica en el deseo de evitar continuas impugnaciones de las normas que se consideran elementos básicos del ordenamiento y, consecuentemente, manifestación de la voluntad general.

Ahora bien, la legitimación constitucional, a pesar de ser restringida presenta algunos problemas. Así por ejemplo, la legitimación otorgada al Defensor del Pueblo debería, en principio, restringirse al campo de la protección de los derechos fundamentales, que es su única tarea por mandato del artículo $54^{\circ}$ de la Constitución española. Debe recordarse que ello no limitaría sus competencias por cuanto el concepto de protección de los derechos fundamentales tiene un amplio alcance, siendo que pocas son las normas que directa o indirectamente no puedan conectarse con dicha tarea. ${ }^{9}$

Por otro lado, la legitimación que tienen cincuenta Diputados o Senadores, es un mecanismo de protección de minorías parlamentarias frente a la mayoría. También permite a las fuerzas políticas con suficiente representación parlamentaria a reaccionar frente a normas con fuerza de ley, dictadas tanto en el ámbito estatal como en el autonómico. De esta forma, se incide en el campo de la organización territorial del Estado. 
Asimismo, la legitimación de órganos autonómicos, tanto ejecutivos como legislativos, es un aspecto importante del diseño de distribución territorial de poder. Recuérdese que en España existe sólo un Tribunal Constitucional, y no uno por cada Comunidad Autónoma, siendo que los conflictos de competencia legislativa son resueltos por dicho órgano a través de un recurso de inconstitucionalidad. Sin embargo, esta legitimación es la que más problemas ha planteado en la práctica. Ello, porque el artículo $32^{\circ} .2$ de la Ley Orgánica del Tribunal Constitucional, al regular esa legitimación, exige que las normas con fuerza de ley del Estado que se impugnen por los citados órganos autonómicos "puedan afectar a su ámbito de autonomía"10, lo cual evidentemente tiene un amplio alcance de interpretación.

El plazo para interponer el recurso de inconstitucionalidad es de tres meses a partir de la publicación de la norma cuestionada (artículo $33^{\circ}$ Ley Orgánica) ${ }^{11}$. Al respecto, debe señalarse que este plazo es ciertamente muy corto, razón por la que debe garantizarse en mayor medida, la posibilidad de los ciudadanos de interponer los procesos constitucionales de tutela de la libertad contra las denominadas normas "autoaplicativas".

Elartículo $164^{\circ}$ dela Constitución regula losefectos delas sentencias delTribunal Constitucional, en general, y de las que declaran la inconstitucionalidad de las normas con fuerza de ley en concreto ${ }^{12}$. De la compleja regulación sobre la materia, cabe destacar lo siguiente:

- Las sentencias del Tribunal Constitucional despliegan sus efectos desde el día siguiente de su publicación en el Boletín Oficial del Estado ${ }^{13}$.

- En el aspecto de su contenido, la declaración de inconstitucionalidad supone, según el artículo $39^{\circ} .1$ de la Ley Orgánica, la nulidad de los preceptos afectados. Entonces, es posible declarar una inconstitucionalidad parcial de la norma.

- El artículo $40^{\circ}$ de la Ley Orgánica establece que la declaración de inconstitucionalidad no permite revisar procesos fenecidos mediante sentencia con efectos de cosa juzgada en los que se haya hecho aplicación de la norma inconstitucional ${ }^{14}$.

- Es de resaltar, que considerando los problemas que puede generar en la práctica la declaración de inconstitucionalidad de una norma con fuerza de ley, el Tribunal Constitucional haya flexibilizado ${ }^{15}$ en ocasiones los efectos, adecuándolos a las circunstancias del caso concreto, llegando, 
incluso, a limitar sus efectos temporalmente a partir de la declaración de inconstitucionalidad, o permitiendo que la norma inconstitucional siga vigente hasta que otra norma válida la desplace. ${ }^{16}$

\section{LA CUESTIÓN DE INCONSTITUCIONALIDAD}

La cuestión de inconstitucionalidad es el segundo instrumento procesal mediante el cual se puede controlar la constitucionalidad de las normas con rango de ley. Constituye un complemento del recurso de inconstitucionalidad (que permite un control directo de la norma), en tanto permite reaccionar contra la inconstitucionalidad de una norma con fuerza de ley a través de su aplicación concreta. ${ }^{17}$

En efecto, el artículo $163^{\circ}$ de la Constitución española dispone que "cuando un órgano judicial considere, en algún proceso, que una norma con rango de ley, aplicable al caso, de cuya validez depende el fallo, pueda ser contraria a la Constitución, planteará la cuestión de inconstitucionalidad ante el Tribunal Constitucional en los supuestos, en la forma y con los efectos que establezca la ley, que en ningún caso serán suspensivos".

De esta manera, la cuestión de inconstitucionalidad es un mecanismo que permite a un juez reaccionar frente a cualquier inconstitucionalidad que pueda advertir en un caso determinado respecto de una norma con rango de ley, sin que sea necesaria la intervención de quien está legitimado para interponer el recurso directo. Además, hace posible no abrir la legitimación para recurrir normas con fuerza de ley a cualquier persona. ${ }^{18}$

La cuestión de inconstitucionalidad es una suerte de control difuso indirecto, pues los órganos judiciales actúan como filtro para hacer llegar al Tribunal Constitucional los casos de inconstitucionalidad que tengan un mínimo de fundamento y que posean una dimensión concreta y efectiva. Así, la cuestión de inconstitucionalidad hace posible vincular el monopolio de rechazo de las normas que corresponde al Tribunal Constitucional con la efectiva supremacía de la norma fundamental, que vincula a todos los órganos judiciales ${ }^{19}$.

Por ello, la cuestión de inconstitucionalidad, según sentencia del Tribunal Constitucional ${ }^{20}$ configura "(..) un mecanismo de depuración del ordenamiento jurídico, a fin de evitar que la aplicación judicial de una norma con rango de ley produzca resoluciones judiciales contrarias a la Constitución por serlo la norma aplicada". 
De conformidad con el artículo $163^{\circ}$ de la Constitución, cualquier órgano judicial puede plantear la cuestión de inconstitucionalidad ante el Tribunal Constitucional, siempre que se cumplan ciertos requisitos. El presupuesto de la acción es que la duda sobre la constitucionalidad de la norma con fuerza de ley ha de surgir dentro de un procedimiento judicial ${ }^{21}$, ya sea planteada por el juez como por alguna de las partes de dicho procedimiento (Artículo 35․1 Ley Orgánica).

Es deprecisarseque para el planteamiento delacuestión deinconstitucionalidad no basta con el simple surgimiento de la duda, por lo que se exige que esta debe de ser relevante para la decisión del proceso en que se propone, de forma que la decisión dependa de la regularidad o no de la norma cuestionada y justifique un análisis por parte del Tribunal. De igual manera, la duda sobre la constitucionalidad de la norma con rango de ley debe estar suficientemente fundamentada y motivada por el órgano judicial que eleva la cuestión ante el Tribunal Constitucional.

Como puede notarse, la interpretación de la norma y la duda de constitucionalidad son elementos íntimamente relacionados, y por tanto, motivan a que en el examen de la duda de constitucionalidad que se realiza se haga referencia a una previa interpretación de la norma y a la forma en que puede condicionar la decisión del juez sobre la posible inconstitucionalidad de la misma.

Lo anterior tiene base en que la cuestión de inconstitucionalidad cobra sentido únicamente cuando el juez se encuentra ante una discordancia entre Constitución y norma con rango de ley aplicable en el proceso, que no puede solucionar por otros medios. Esa discordancia que el juez advierte tendrá como condición una determinada interpretación de la norma que se pretende cuestionar y del precepto constitucional que se considera vulnerado, y en este sentido la interpretación en tanto presupuesto de la duda de constitucionalidad condiciona la decisión del juez respecto del planteamiento de la cuestión de inconstitucionalidad.

La cuestión de inconstitucionalidad se puede interponer en cualquier proceso seguido ante un órgano jurisdiccional, sea cual sea el orden o jurisdicción. Al órgano judicial, como se ha referido, le corresponde controlar que se cumplan los requisitos legalmente exigidos: relevancia de la cuestión para el fallo y fundamentación suficiente de la duda de constitucionalidad ${ }^{22}$. Si estos requisitos no se cumplen, el órgano judicial ha de rechazar el planteamiento de la cuestión. Más aún, el órgano judicial, una vezconstatado el cumplimiento de los requisitos, debe analizar la duda formulada para determinar si, por vía interpretativa, es salvable la contradicción entre norma con fuerza de ley y Constitución (Artículo 
$5^{\circ} .3$ de la Ley Orgánica del Poder Judicial), es decir, el órgano judicial, al estar vinculado por la Constitución, debe buscar una interpretación de la norma cuestionada que la haga compatible con la Carta Constitucional, siendo que sólo si no encuentra esa interpretación o si estima que ésta es insatisfactoria, presentará la cuestión ante el Tribunal Constitucional.

Ahora bien, el planteamiento de la cuestión sólo puede hacerse una vez concluido el procedimiento y hasta antes de adoptar la resolución correspondiente (Artículo $35^{\circ} .2$ de la Ley Orgánica del Tribunal Constitucional $)^{23}$. No obstante que este precepto se refiere exclusivamente a aquellos procedimientos que finalizan por sentencia, el Tribunal Constitucional ha establecido que la cuestión puede formularse también ante decisiones judiciales que adopten otra forma (auto o providencia) por tratarse de dudas que surjan en procedimientos incidentales. El requisito de tener que esperar a que el procedimiento termine tiene una doble finalidad, por un lado, el evitar que la cuestión de inconstitucionalidad sea utilizada con fines exclusivamente dilatorios, y por el otro, privilegiar la idea de que sólo estando concluso el procedimiento puede valorarse en su real dimensión la relevancia de la norma cuestionada ${ }^{24}$.

En el caso de que el órgano judicial estime que no procede plantear la cuestión de inconstitucionalidad, su resolución no puede recurrirse, sin perjuicio de que pueda volverse a suscitar la duda en posteriores instancias jurisdiccionales.

Entonces, una vez presentada la cuestión ante el Tribunal Constitucional culmina la primera fase de la cuestión de inconstitucionalidad, la que se desarrolla en el proceso original, que es donde la duda surge. A partir de allí, se abre el proceso constitucional propiamente dicho, en el que se decide sobre la validez de la norma cuestionada. Este proceso se desarrolla totalmente ante el Tribunal Constitucional y en él no participan las partes en el proceso que motivó la cuestión. Sin embargo, sus alegaciones constan, ya que se remiten junto con el auto de planteamiento de la cuestión. Al respecto, y como era de esperarse, esta exclusión de las partes del proceso original en el proceso constitucional ha sido rebatida por el Tribunal Europeo de Derechos Humanos, al menos para aquellos casos en los que se enjuicien normas con fuerza de ley de tipo singular. ${ }^{25}$

Admitida la cuestión a trámite, el procedimiento a seguir es parecido al del recurso de inconstitucionalidad. Se corre traslado al Fiscal General del Estado, a las Cámaras, al Gobierno y, cuando corresponda, a los ejecutivos y legislativos de la Comunidad Autónoma que hubiera dictado la norma cuestionada con la finalidad de que se apersonen y formulen alegaciones si lo estiman conveniente. Oídas las partes, el Pleno del Tribunal Constitucional 
dicta sentencia pronunciándose sobre la constitucionalidad o no de la norma que se cuestiona. El Tribunal Constitucional notificará su decisión al juez o tribunal que planteó la cuestión para que resuelva el proceso originario.

\section{LA CUESTIÓN INTERNA DE INCONSTITUCIONALIDAD}

Algunos trabajos doctrinales apuntan a señalarlo como un verdadero amparo directo contra leyes ${ }^{26}$ aunque en la práctica se ha conseguido eliminar dicha tendencia. En todo caso, tomo como base la experiencia alemana, donde se prevé un recurso directo frente a leyes pero limitado únicamente leyes autoaplicativas, es decir, a aquellas leyes que por su publicación y sin mediar ningún acto de aplicación, lesionan derechos fundamentales de los particulares.

Así, el primer supuesto con el que debió enfrentarse el Alto Tribunal Español fue el caso de anulación del artículo $28^{\circ} .2$ de la Ley de Derechos Pasivos de los Funcionarios de 1966. Así, después de recurrir diversas resoluciones administrativas que le denegaban diversos derechos pasivos, un funcionario acudió mediante un proceso de amparo al Tribunal Constitucional. La razón por la que le habían denegado el beneficio de dichos derechos, consistía en que ellos eran generados en un segundo periodo de servicios a la Administración Pública, de la que fue separado por jubilación forzosa. Entonces, al ocurrir su reincorporación perdía, según el artículo $28^{\circ}$.2, la percepción de los derechos pasivos.

Todos los tribunales administrativos consideraron, en estricto cumplimiento de la legalidad, que no era procedente el reclamo, por lo que se denegó la petición. Ante ello, se recurrió al amparo ante el máximo Tribunal, alegándose la inconstitucionalidad de la legalidad que defendían los tribunales inferiores, pues contravenía directamente el principio de igualdad reconocido en el artículo $14^{\circ}$ de la Constitución Española.

El Tribunal Constitucional estimó el amparo, considerando inconstitucional el artículo $28^{\circ}$.2. de la Ley de Derechos Pasivos. Así, la Sala, en aplicación de la Ley Orgánica del Tribunal Constitucional, resolvió el amparo mediante sentencia de fecha 6 de abril de 1981, y posteriormente elevó al Pleno la cuestión para la resolución de la inconstitucionalidad de la norma. El Pleno declaró la inconstitucionalidad sobrevenida y la consiguiente nulidad del precepto cuestionado.

Este es el primer caso en que pasaba ello gracias a la transformación de un amparo en cuestión de inconstitucionalidad. Entonces, es posible llegar a la inconstitucionalidad de una ley que viole derechos fundamentales a través de un proceso de amparo, pero no en un proceso de amparo. De esta manera, 
el particular alegará la inconstitucionalidad de la ley en su amparo pero no pretenderá que la Sala que conozca del asunto emita una sentencia en la que se falle la inconstitucionalidad de la norma. ${ }^{27}$

El desdoblamiento deprocesos genera que haya un repetimiento de argumentos debatidos en el proceso de amparo. La Sala prejuzga la decisión del Pleno o puede determinar una situación provisional. La norma será considerada inconstitucional hasta el momento en que el Pleno dicte sentencia, en tanto no lo haga, los tribunales ordinarios seguirán aplicando la norma. ${ }^{28}$

Ahora bien, el otro caso que podemos citar es el de la sentencia del Tribunal Constitucional de fecha 18 de diciembre de 1981. En dicho asunto varios particulares atacaron diversas resoluciones judiciales, a través de las que se les impidió presentarse y actuar en los juicios hipotecarios seguidos en su contra. Al igual que el caso anterior, las resoluciones emitidas por los tribunales ordinarios se encontraban apegadas a la legalidad.

Los recurrentes argumentaron la violación del artículo $24^{\circ}$ de la Constitución que establece la tutela jurisdiccional. Solicitaron la elevación de la cuestión al Pleno para la declaración de inconstitucionalidad correspondiente.

Esta sentencia tiene relevancia porque estableció la posibilidad de atacar leyes por inconstitucionalidad, pretendiendo su anulación. Empieza la sentencia señalando la necesidad de cuestionarse si un particular puede impugnar, por inconstitucionales, preceptos legales sin acudir previamente a la cuestión de inconstitucionalidad. Después se establece que "una interpretación racional de este precepto $\left(55^{\circ} .2\right.$.) obliga a entender que la inconstitucionalidad de la ley que lesione derechos fundamentales y libertades públicas puede ser alegada por el recurrente del proceso de amparo. De este modo puede admitirse una pretensión directa de inconstitucionalidad sostenida por particulares" 29 .

Por su lado, el Tribunal Constitucional ha considerado a la cuestión interna, como una simple cuestión de inconstitucionalidad, pero sin lugar a dudas no es la misma figura prevista por el artículo $63^{\circ}$ de la Constitución Española. La diferencia radica en que en un recurso de amparo por parte de las Salas del Tribunal Constitucional, y siempre que sea estimado, es potestativo para el máximo Tribunal.

Finalmente, es importante traer a colación los dos momentos procesales que vive la cuestión interna: por un lado, el amparo será resuelto por la Sala correspondiente y finalizará con la sentencia emitida por esta (el contenido se ceñirá a lo dispuesto por el artículo $55^{\circ} .1$ ), por otro lado, la cuestión planteada 
al pleno se tramitará conforme al artículo $37^{\circ}$ y siguientes como si se tratara de una cuestión de inconstitucionalidad.

\section{CONCLUSIONES}

- Con la restauración de la democracia en España, reflejada en el sistema constitucional de la Carta de 1978, empieza en este Estado un efectivo control de las leyes a la luz de su correspondencia con la Constitución. Ello evidencia la relación natural entre la democracia y el principio de supremacía constitucional.

- El mecanismo de control de la constitucionalidad de las leyes en España, si bien se basa en un control concentrado a cargo de un Tribunal Constitucional, tiene rasgos de un control difuso impropio, dada la calidad de observadores de la constitucionalidad que ejercen los jueces ordinarios.

- En el sistema de control de constitucionalidad de las leyes, el Tribunal Constitucional juega un papel medular. Por ello, es de resaltar que en España esté plenamente reconocido que dicho órgano es el intérprete supremo de la Constitución, es un órgano constitucional e independiente y no forma parte del Poder Judicial, estando sólo sometido a la Constitución y a su propia Ley Orgánica.

- El mecanismo de control abstracto de supremacía de la Constitución se encuentra garantizado por el recurso de inconstitucionalidad, siendo que a través de este, el Estado español depura su ordenamiento con la sentencia estimatoria dada por el Tribunal Constitucional, que tiene efectos erga omnes.

- De otro lado, la cuestión de inconstitucionalidad representa el mecanismo de control concreto de las normas, no logrando declaraciones generales como sucede en el recurso de inconstitucionalidad, sino que permite la emisión de un fallo, que sirve al juez ordinario para poder resolver el caso concreto. El proceso que observa la ley se suspenderá hasta que el Tribunal Constitucional emita la sentencia correspondiente.

- Entonces, la cuestión de inconstitucionalidad es una suerte de control difuso indirecto, pues los órganos judiciales actúan como filtro para hacer llegar al Tribunal Constitucional los casos de inconstitucionalidad que tengan un mínimo de fundamento y que posean una dimensión concreta y efectiva.

- La cuestión interna es otro mecanismo de control de constitucionalidad. En la práctica es un verdadero amparo directo contra leyes ${ }^{30}$. Permite 
admitirse una pretensión directa de inconstitucionalidad sostenida por particulares en relación con afectación de derechos fundamentales y libertades públicas.

- A la luz del modelo de control de constitucionalidad de las leyes, del rol que desempeña el Tribunal Constitucional como supremo intérprete de la Constitución, y de los mecanismos previstos para el mencionado control, se puede concluir que España ha institucionalizado un sistema que permite garantizar a los particulares y a los órganos del Estado una permanente participación en la observación de las normas a la luz de los mandatos constitucionales. Ello, hace posible una mejor consolidación del Estado Constitucional de Derecho, en tanto todos los actores del Estado y de la sociedad se encuentran comprometidos en la defensa de la Constitución.

\footnotetext{
Para Kelsen el Tribunal Constitucional asume funciones legislativas, pero solamente de carácter negativo: aplicando la Constitución a un hecho concreto de producción legislativa y llegando a anular leyes anticonstitucionales no genera sino destruye una norma general, es decir, pone el actus contrarius correspondiente a la producción jurídica, o sea, que oficia de "legislador negativo". Kelsen, Hans. La garantía jurisdiccional de la Constitución: la justicia constitucional. Traducción de J.M. Ruiz Manero, Mc Graw Hill. Madrid: 1988. Págs. 109 y ss.

2 El origen de la institución denominada Tribunal Constitucional tiene su origen en las antiguas Cortes de Casación, que era una desmembramiento del poder del legislador destinado a recibir los casos en los que lo jueces no podían interpretar la ley en los casos de lagunas o contradicciones. La imagen de estas Cortes de Casación ha evolucionado hasta convertirse hoy en día en un tribunal más propio de la Magistratura que de la función legislativa, pero en su origen fue la desconfianza en el juez y el deseo de preservar la soberanía de la función legislativa. A. Vanossi, Jorge Reinaldo. Teoría Constitucional: Supremacía y control de constitucionalidad. Tomo II, $2^{\circ}$ edición. Buenos Aires: Depalma, 2000. Pág. 103.
}

3 La protección y garantía de los derechos fundamentales no es una tarea única del Tribunal Constitucional, sino que los tribunales ordinarios desempeñan un papel esencial y crucial en ella. Preámbulo de la Ley Orgánica 6/2007. En su redacción original, la Ley Orgánica del Tribunal Constitucional carecía de Preámbulo.

4 Esta norma ha constituido el instrumento indispensable para la realización de las tareas a cargo del Tribunal Constitucional y los procedimientos en ella previstos han incidido en la vida y la conciencia jurídica españolas.

5 El Tribunal Constitucional podrá dictar reglamentos sobre su propio funcionamiento y organización, así como sobre el régimen de su personal y servicios, dentro del ámbito de la presente Ley. Estos reglamentos, que deberán ser aprobados por el Tribunal en Pleno, se publicarán en el "Boletín Oficial del Estado", autorizados por su Presidente. Ley Orgánica del Tribunal Constitucional español.

6 Artículo $5^{\circ}$ de la Ley Orgánica del Tribunal Constitucional Español.

7 El artículo $93^{\circ}$ de la Constitución Española señala lo siguiente: "Mediante ley orgánica se podrá autorizar la celebración de tratados por los que se atribuya a una organización o institución internacional el ejercicio de competencias derivadas de la Constitución. Corresponde a las Cortes Generales o al Gobierno, según los casos, la garantía del cumplimiento de estos tratados y de las resoluciones emanadas de los organismos internacionales o supranacionales titulares de la cesión".

8 Sentencia del Tribunal Constitucional N 5/1981, donde se estableció: "La facultad de promover el recurso de inconstitucionalidad no lo otorga la Constitución en atención a un interés propio de quienes la reciben sino en virtud de la alta calificación política que resulta de su respectivo cometido constitucional."

9 Pérez Royo, Javier. La regulación de algunos aspectos del recurso de inconstitucionalidad: su influencia sobre la naturaleza del Tribunal Constitucional en la Constitución Española de 1978. Madrid: Tecnos, 1981. Pág. 2181 y ss. 
10 Sentencia del Tribunal Constitucional $\mathrm{N}^{\circ}$ 56/90. De acuerdo con la jurisprudencia del Tribunal Constitucional, se desprende que este precepto ha sido objeto de una interpretación evolutiva, de forma que sirve como instrumento no sólo de reivindicación de competencias que pudieran verse invadidas por normas estatales con fuerza de ley, sino también de impugnación de preceptos que puedan incidir indirectamente en esas competencias o, incluso, en intereses de la Comunidad Autónoma sin dimensión competencial concreta.

11 El recurso de inconstitucionalidad se formulará dentro del plazo de tres meses a partir de la publicación de la Ley, disposición o acto con fuerza de Ley impugnado mediante demanda presentada ante el Tribunal Constitucional, en la que deberán expresarse las circunstancias de identidad de las personas u órganos que ejercitan la acción y, en su caso, de sus comisionados, concretar la Ley, disposición o acto impugnado, en todo o en parte, y precisar el precepto constitucional que se entiende infringido. Artículo $33^{\circ} .1$ de la Ley Orgánica del Tribunal Constitucional Español.

12 Artículos $38^{\circ}$ y ss. de la Ley Orgánica del Tribunal Constitucional.

13 Las sentencias del Tribunal Constitucional se publicarán en el boletín oficial del Estado con los votos particulares, si los hubiere. Tienen el valor de cosa juzgada a partir del día siguiente de su publicación y no cabe recurso alguno contra ellas. Las que declaren la inconstitucionalidad de una ley o de una norma con fuerza de ley y todas las que no se limiten a la estimación subjetiva de un derecho, tienen plenos efectos frente a todos. Artículo $164^{\circ} .1$ de la Constitución Española.

14 Sólo se prevé una excepción: que dicha aplicación haya supuesto una sanción penal o administrativa que no existiría o se vería reducida como consecuencia de la nulidad de la norma aplicada.

15 Sentencia del Tribunal Constitucional $N^{\circ} 45 / 89$.

16 Sentencia del Tribunal Constitucional Nº 195/1998.

17 Corzo Sosa, Edgar. La cuestión de inconstitucionalidad. Madrid: CEPC, 1998. Pág. 64 y ss.

18 Sentencia del Tribunal Constitucional No 17/1981, donde se estableció que: "la cuestión de inconstitucionalidad no es una acción concedida para impugnar de modo directo y con carácter abstracto la validez de la ley, sino un instrumento puesto a disposición de los órganos judiciales para conciliar la doble obligación en que se encuentran de actuar sometidos a la ley y a la Constitución".

19 Cruz Villalón, Pedro. La formación del Sistema europeo de control de constitucionalidad. Marcial Pons. Madrid: 1987. Pág. 43. El autor denomina a este, control concreto impropio, por la semejanza con el sistema difuso o americano.

20 Sentencia del Tribunal Constitucional N²127/87.

21 Pérez, Tremps. Tribunal Constitucional y Poder Judicial. Madrid: Tecnos, 1985. Pág. 131.

22 Cuando un Juez o Tribunal, de oficio o a instancia de parte, considere que una norma con rango de Ley aplicable al caso y de cuya validez dependa el fallo pueda ser contraria a la Constitución, planteará la cuestión al Tribunal Constitucional con sujeción a lo dispuesto en esta Ley. Artículo $35^{\circ} .1$ de la Ley Orgánica del Tribunal Constitucional Español.

23 El órgano judicial sólo podrá plantear la cuestión una vez concluso el procedimiento y dentro del plazo para dictar sentencia, o la resolución jurisdiccional que procediese, y deberá concretar la ley o norma con fuerza de ley cuya constitucionalidad se cuestiona, el precepto constitucional que se supone infringido y especificar o justificar en qué medida la decisión del proceso depende de la validez de la norma en cuestión. Antes de adoptar mediante auto su decisión definitiva, el órgano judicial oirá a las partes y al Ministerio Fiscal para que en el plazo común e improrrogable de 10 días puedan alegar lo que deseen sobre la pertinencia de plantear la cuestión de inconstitucionalidad, o sobre el fondo de esta; seguidamente y sin más trámite, el juez resolverá en el plazo de tres días. Dicho auto no será susceptible de recurso de ninguna clase. No obstante, la cuestión de inconstitucionalidad podrá ser intentada de nuevo en las sucesivas instancias o grados en tanto no se llegue a sentencia firme. Artículo $35^{\circ} .2$ de la Ley Orgánica del Tribunal Constitucional Español.

24 Sentencia del Tribunal Constitucional N ${ }^{\circ} 76 / 1992$

25 Sentencia del Tribunal Europeo de Derechos Humanos, Caso Stedh Ruiz Mateos contra España, de fecha 23 de junio de 1993.

26 Urias Martínez. La cuestión interna de inconstitucionalidad. Madrid: Civitas ediciones, 1996. Pág. 58.

27 Figueruelo, Ángela. Algunos problemas que suscita la autocuestión de inconstitucionalidad. Madrid: REDC 21, 1987. Pág. 239.

28 Ibidem, Pág. 240.

29 Borrajo Iniesta. Amparo contra leyes. Madrid: RAP, 2001. Pág. 167 y ss.

30 Urias Martínez. Op. Cit. Pág. 78. 